\title{
Uncovering the Link between Strategic Human Resource Management and Crisis Management: Mediating Role of Organizational Resilience
}

\author{
Nisar Ahmed Channa*, Syed Mir Muhammed Shah and Niaz Hussain Ghumro \\ Business Administration Department, Sukkur IBA University, Sukkur Sindh, Pakistan \\ nisarahmed.msmgt17@iba-suk.edu.pk; syedmir@iba-suk.edu.pk; niaz ghumro@iba-suk.edu.pk \\ ${ }^{*}$ Correspondence: nisarahmed.msmgt17@iba-suk.edu.pk
}

Received: $2^{\text {nd }}$ June 2019; Accepted: 29 ${ }^{\text {th }}$ June 2019; Published: $1^{\text {st }}$ August 2019

Abstract: The paper has attempted to examine a critical link between the strategic human resource management and crisis management. In this, the authors have taken a major drive to statistically test mediation and moderation simultaneously. Drawing upon the normal accident theory, the present study examined the link between strategic human resource management (SHRM) and crisis management through the mediation of organizational resilience. By adopting quantitative research approach, the data were collected from 176 HR managers of textile firms in Pakistan through survey method. The data were analysed by employing PLS-SEM technique. Results revealed that SHRM is positively linked with crisis management through the mediating effect of organizational resilience. In general, the results revealed that organizational resilience plays a key role in facilitating the relationship between SHRM and crisis management. The paper forwards notable implications for theory and practice followed by scope for future studies to enthusiastic scholars in the domain of HRM, strategic HRM and crisis management.

Keywords: Organizational resilience; Crisis management; Strategic human resource management; Normal accident theory; Mediation; Moderation

\section{Introduction}

The organizational crisis has a low probability of occurrence but they are a major threat to the survival of an organization and its stakeholders (Jackson \& Dutton, 1987). It gives very short or often no time to respond and surprise members of the organization (Herman, 1963; Quarantelli, 1988). Academic research viewed crisis management as a combination of factors designed to deal with and minimize damage caused by the crisis (Coombs, 2015). Crisis management deals with effective planning to prevent a crisis, minimize damages and resume operations at the time when the organization became unable to perform core activities to produce output and cater needs of customers (Pearson \& Clair, 1998). 
In surprising, turbulent and continuously evolving marketplace environments only agile, flexible and dynamic organizations will survive (Lengnick-Hall et al., 2011). Therefore, organizations must be able not only to survive but also to prosper in uncertain, threatening and complicated environments. Unstable environments create chaos and challenges, even marketplaces that are considered relatively stable experience jolts and undergo revolutionary shifts (Ahmed, Khalid, Islam \& Abro, 2019; Lengnick-Hall et al., 2011). Normally these events are viewed as negatively, but Sutcliffe and Vogus (2003), conceptualized that under challenging conditions resilient organizations maintain positive adjustments. Therefore, it can be inferred that resilient organizations have a competitive advantage over non-resilient organizations. It is because resilient organizations have the capacity to adopt changes more quickly and adjust with both internal and external environmental changes (Lengnick-Hall et al., 2011). Resilient organizations flourish because they already faced and succeeded in challenging situations. Existing literature in domains of crisis management and organizational resilience provides evidence that both of them are linked with each other in a positive way (Tokakis et al., 2019; Kahn et al., 2018; Parker \& Ameen, 2018; Prezelj \& Doerfel, 2017; Teo et al., 2017; Lengnick-Hall et al., 2011).

However, there is a paucity in the literature about how organizations can develop the capacity of resilience (Ishak \& Williams, 2018). Most of the studies found in the literature (Parker \& Ameen, 2018; Prezelj \& Doerfel, 2017; Sutcliffe and Vogus, 2003) suggest the implications and outcomes of organizational resilience during the crisis. Very limited attention has been paid so far towards the actions that create resilience in organizations (Galdeano, Ahmed, Fati, Rehan \& Ahmed, 2019; Ishak $\&$ Williams, 2018). One of the antecedents of organizational resilience is strategic human resource management (SHRM) as suggested by (Stokes et al, 2018). It is evident from the literature that by aligning HRM practices with the concept of or organizational ambidexterity a firm can develop capabilities of organizational resilience (Strokes et al., 2018). In similar vein, Lengnick-Hall et al. (2011) reported that SHRM creates competencies among employees, which makes it possible to develop situation-specific responses to threats and crisis, absorb uncertainty, and engage in transformative activities so that disruptive surprises that potentially threat survival of organization can be exploited. Research on normal accident theory suggests that rather than putting efforts on avoiding crises, organizations can turn crises into opportunities by planning and developing strategies to cope with the crisis (Shrivastava, 2009; Rijpima, 1997; Perrow, 1984). By creating core competencies and situation specific responses among employees through SHRM, the organization will eventually develop capabilities of organizational resilience, which strengthen organization to manage a crisis effectively (Coombs \& Laufer, 2018; Gittell et al., 2006). Therefore, the main objective of this research is to build and test a research model suggesting that by incorporating the SHRM practices, an organization can develop capabilities of organizational resilience, which strengthens the organization to manage crises effectively.

In domains of organizational resilience and crisis management, most of the studies are conducted in developed countries and there is need to get a better understanding of crisis management in developing countries (Coombs \& Laufer, 2018). Further, it is believed that country characteristics like cultural characteristics, rule of law and competitiveness influence crisis, reactions of stakeholders, and effectiveness of corporate responses (Cleeren et al., 2017). Majority of previous studies are of qualitative nature and quantitative studies to provide empirical evidence to these propositions are missing in the literature. Therefore, the second objective of this study is to provide empirical support to normal accident theory by conducting this study in the context of a developing economy. In summary, the prime objective of this study is to investigate how SHRM helps an organization to manage a crisis effectively. To this end, we contributed to developing a mediation model to explain the mechanism of how SHRM is positively related to crisis management in the textile sector. This study contributed in three ways. First, our research validates that SHRM has a positive relationship with crisis management and SHRM is an antecedent of organizational resilience. Second, current study confirms the mediation of organizational resilience in the relationship between SHRM and crisis management, which validates our model that by incorporating SHRM practices, organizational resilience capabilities can be developed, that strengthens an organization's abilities to 
effectively cope crisis (Madrid, Ahmed \& Kumar, 2019). Third, our study provides empirical evidence to the claim of normal accident theory that instead of putting efforts to avoid crises, organizations should put efforts on getting prepared to face crisis and change crisis and threats into opportunities.

\section{Literature Review}

\subsection{Crisis Management}

Crisis management is defined by Coombs (2015) a a combination of factors designed to deal with and minimize damage caused by the crisis. According to (Pearson \& Clair, 1998), crisis management deals with effective planning to prevent a crisis, minimize damages and resume operations at the time when the organization became unable to perform core activities to produce output and cater needs of customers.

The literature on emergency preparedness suggests there are four interrelated factors: prevention, preparation, revision, and response. Coombs and Laufer (2018), classified these factors in a three-stage approach commonly used to describe crisis management: pre-crisis phase, the crisis phase, and the post-crisis phase. Pre-crisis phase involved in strategizing to prevent and prepare for a crisis, crisis-phase involved in strategizing to response crisis, and post-crisis phase involved strategizing for learning from the crisis. During the financial crisis of 2008, the performance of multinational organizations was influenced by Pre-crisis asset management (Fainshmidt et al., 2017). The capacity of multinational organizations to deal with the global financial crisis was enhanced by routine altering activities of asset management capabilities (Coombs \& Laufer, 2018).

\subsection{Normal Accident Theory}

Normal accident theory (NAT) is the underpinning theory behind this study. NAT emphasizes that accidents are unavoidable in complex environments (Shrivastava, 2009; Rijpima, 1997). Complexity unavoidably causes interactions between failures, on the other hand, the tight coupling of these interactions increases rapidly and do not prevent system breakdowns (Rijpima, 1997). Perrow (1984), explains that accidents are normally caused by the failure of a lower level of the component which rapidly proceeds to higher levels and defeat engineered safety features. Better designing of engineered safety features, preventive maintenance, and training can avoid accidents and failures (Perrow, 1984).

NAT supports the argument that in today's world organizational crisis become inevitable and one cannot avoid crisis and uncertainty. Rather than putting efforts to avoid crisis, surprises, and threats, one should try to put efforts on getting prepared to face crisis and change crisis and threats into opportunities. Crisis can be avoided and damage caused by the crisis can be minimized by developing strategies and planning to cope with the crisis (Coombs \& Laufer, 2018). Strategic human resource management enables an organization to create core competencies and capabilities among employees that enable the organization to develop situation-specific responses to threats and uncertainties. Organizational resilience is one of the capabilities that help organizations to get prepare for and cope with the crisis, as Gittell et al. (2006) stated that organizational resilience is an organization's ability to recover from stressful, turbulent, adverse situations, and picked up from where they left off.

\subsection{Strategic HRM and Crisis Management}

Previous studies conducted to find common grounds between SHRM and crisis management suggest that both are linked in the exorable way (Pauchant \& Mitroff, 1992; Mitroff et al., 1992). However, more research is needed to specify links between SHRM and crisis management (Preble, 1997). It is further proposed by Preble (1997) that a defensive capability to prevent and lessen the effects of crisis occurs by incorporating crisis management perspective into the strategic management process. A more comprehensive approach to manage organizational strategy can be produced by incorporating preventive capabilities of crisis management (Umrani, Ahmed \& Memon, 2015; Preble, 1997). There are six points that link strategic management with crisis management: a concern for the 
whole organization, the involvement of top management, a focus on a complex set of stakeholders, environmental relations, representation of emergent processes, and expression of a consistent pattern (Mitroff et al., 1992). However, there is a paucity in the existing literature on the empirical evidence to test this relationship considering that very limited focus on this direct relationship. On basis of above-cited studies and normal accident theory, it is believed that by integrating crisis management perspective with strategic human resource management a defensive capability to prevent crisis and to lessen effects of a crisis if a crisis occurs. Thus, we formally propose the following hypothesis:

H1: There is a positive relationship between SHRM and crisis management.

\subsection{Strategic HRM and Organizational Resilience}

Lengnick-Hall et al. (2011), proposed that an organization can develop the capability of organizational resilience by incorporating SHRM practices. Resilience creates core competencies among employees that enable organizations to develop situation-specific responses to threats, to absorb uncertainty effectively, and engage in activities that transform organizations and convert threats and surprises into opportunities (Pahi, Hamid, Ahmed \& Umrani, 2015; Lengnick-Hall et al., 2011). It is further suggested that an HR model consists of HR principles, desired employee contributions, and HR policies enable organizations to develop the capacity for resilience. On the basis of the above-cited studies and normal accident theory, it is believed that SHRM enables a firm to develop the capacity for organizational resilience. Thus we formally propose the following hypothesis:

$\mathrm{H} 2$ : There is a positive relationship between SHRM and organizational resilience.

\subsection{Organizational Resilience and Crisis Management}

Stakeholders consider organizational resilience as a key to cope with crisis and improve readiness to deal with threats and disasters (Prezelj \& Doerfel, 2017). Multiple levels comprehensive, and multi-perspective approaches are needed to design response systems like crisis management, disaster management, business continuity, security and safety management (Prezelj \& Doerfel, 2017). One of those approaches is organizational resilience that is comprehensive and multi-perspective because it not only strengthens organizations to cope with current crisis but also enable organizations with capacities to prevent a future crisis (Lengnick-Hall et al., 2011). A study conducted by Parker and Ameen (2018) on small businesses suggest various resilience capabilities of an organization contribute to ingcoping with electricity failures. It is further suggested by Teo et al. (2017) that survival of a firm during the time of crisis depends upon its capabilities of resilience. On the basis of the above-cited studies and normal accident theory, it is believed that organizational resilience enables a firm to manage crises in an effective manner. Thus, we formally propose the following hypothesis:

H3: There is a positive relationship between organizational resilience and Crisis Management.

\subsection{Mediating Role of Organizational Resilience}

It is evident from literature that organizational resilience is associated positively linked with SHRM and crisis management (Prezelji \& Doerfel, 2017; Lengnick-Hall et al., 2011; Parker \& Ameen, 2018; Toe et al., 2017). Lengnick-Hall et al. (2011) proposed that an HR model comprised of desired employee contributions, HR principles and HR policies enable organizations to develop the capacity for resilience. On the other hand, resilience creates core competencies among employees that enable organizations to develop situation-specific responses to threats, to absorb uncertainty effectively, and engage in activities that transform organizations and convert threats and surprises into opportunities (Lengnick-Hall et al., 2011).

On the basis of the above-cited studies, it is believed that SHRM enables an organization to develop the capability for organizational resilience, and organizational resilience helps an organization to effectively manage crises. Thus we formally propose the following hypothesis: 
H4: Organizational resilience mediates the relationship between SHRM and crisis management.

\section{Methodology}

\subsection{Research Context:}

This research has been conducted in the manufacturing context. The current study chose the textile industry of Pakistan as a research context because of many reasons. First, According to the Pakistan Economic Survey (2017-18), Pakistan is one of the largest producers of textile in the world. In Pakistan, the textile industry provides employment opportunities to around 40 percent of total labor force and regarded as the backbone of the country's economy as this industry contributes almost 62 percent to total exports of Pakistan which are being comprised of approximately 8844 million US dollars (PES, 2017-18). These facts show the importance of this industry in the country's economy. Second, nowadays textile industry of Pakistan is in chaos and facing various crises ranging from increased government taxes, unavailability of skilled labor, poor government policies, high energy tariffs, unavailability of energy resources (in form of load shedding). Because of these crises, a rapid downfall in production is seen which cause a reduction in export orders. Due to the pressure of meeting export orders, firms are forced to use alternative means of energy which further increases the cost of production. The high cost of production badly affects the global competitiveness of this industry which causes a reduction in exports orders.

\subsection{Sampling}

To conduct this study, a sample comprised $176 \mathrm{HR}$ managers of textile firms operating in Sindh province of Pakistan is selected by employing the unrestricted sampling technique of probability sampling design. It is because all of the 176 firms included in the sample had an equal chance of being selected for data collection. In probability sampling design, individuals in the chosen population have equal chances to be selected as a sample (Bryman \& Bell, 2015). Unrestricted sampling technique is least biased and offers more generalizability (Hair et al., 2015; Sekaran \& Bougies, 2016; Bryman \& Bell, 2015).

\subsection{Measures}

All items were adapted from previous studies and worded painstakingly to fit according to the context of the study. These items were measured by using a five-point Likert scale ranging from $1=$ strongly disagree to $5=$ strongly agree.. A pilot study was also conducted with a sample of $40 \mathrm{HR}$ managers of textile firms to ensure that the items are clearly understood.

To measure strategic human resource management (SHRM), we adopted 12 items from the scale used in previous studies (Chen and Huang, 2009). The scale consists of five dimensions of SHRM: selection, training, participation, appraisal, and compensation. Organizational resilience was measured by adapting 16 items from the scale used in previous studies (Mallak, 1998). The scale consists of six dimensions: role dependence, resource access, source reliance, solution seeking, critical understanding, and avoidance. In order to measure crisis management, we adapted 12 items from the scale used in previous studies (Israeli and Reichel, 2003). The scale consists of four dimensions: maintenance, marketing, HRM, and government.

\subsection{Data Analysis:}

Data were analyzed through structural equation modeling technique by using Smart PLS 3.0 software. Whereas, SPSS is used to screen data, deal with missing values, outliers, multicollinearity and normality. Smart PLS is used for determining reliability and validity as well as finding out the significance of path coefficients and hypotheses testing. 


\section{Results}

\subsection{Profile of Respondents}

A brief profile of respondents is presented in Table 1. In a sample of $176 \mathrm{HR}$ managers, there were 37 females and 138 males, which makes a percentage of 21 and 79 respectively. Their ages ranged from below 30 and above 40 years. Among them, 45 respondents were below 30 years of age, 79 were between the age of 30 to 35 years, and 20 were 35 to 40 years old which makes a percentage of 27, 63 and 11 respectively. Their education level ranged from a bachelor degree to MS/M.Phil. Among them, 121 respondents hold a bachelor degree, 54 master and 1 holding M. Phil degree that makes a percentage of $68.8,30.7$ and .06 respectively. Likewise, 44 respondents had experience of few than 5 years, 79 respondents had a 5 to 10 years of experience and 53 had more than 10 years of experience making a $25 \%, 45$, and $30 \%$ respectively.

Table1: Respondents Profile

\section{Category Number of Respondents Percent of Respondents}

\section{Experience}

0 to 5 year

5 to 10 Years

More than 10 years

Age

Less than 30 years

30 to 35 years

35 to 40 years

\section{Education}

Bachelor

Master

MS/M.Phil.

\section{Gender}

Male

Female

\section{Designation}

HR Manager

General Manager

Factory Manager

$\begin{array}{rl}44 & 25 \\ 79 & 45 \\ 53 & 30 \\ & \\ 45 & 27 \\ 111 & 63 \\ 20 & 11\end{array}$

121

68.8

54

30.7

1

0.6

138

79

37

21

47

26.7

77

43.8

\section{5} 5

\section{0} 27 63

\section{8}


maintained (Yap et al., 2012; Bagozzi \& Yi, 1991; Gefen et al., 2000; Fornell \& Lacker, 1981). Therefore, there is no issue of reliability and validity in measurement model.

Table 2: Measurement Model

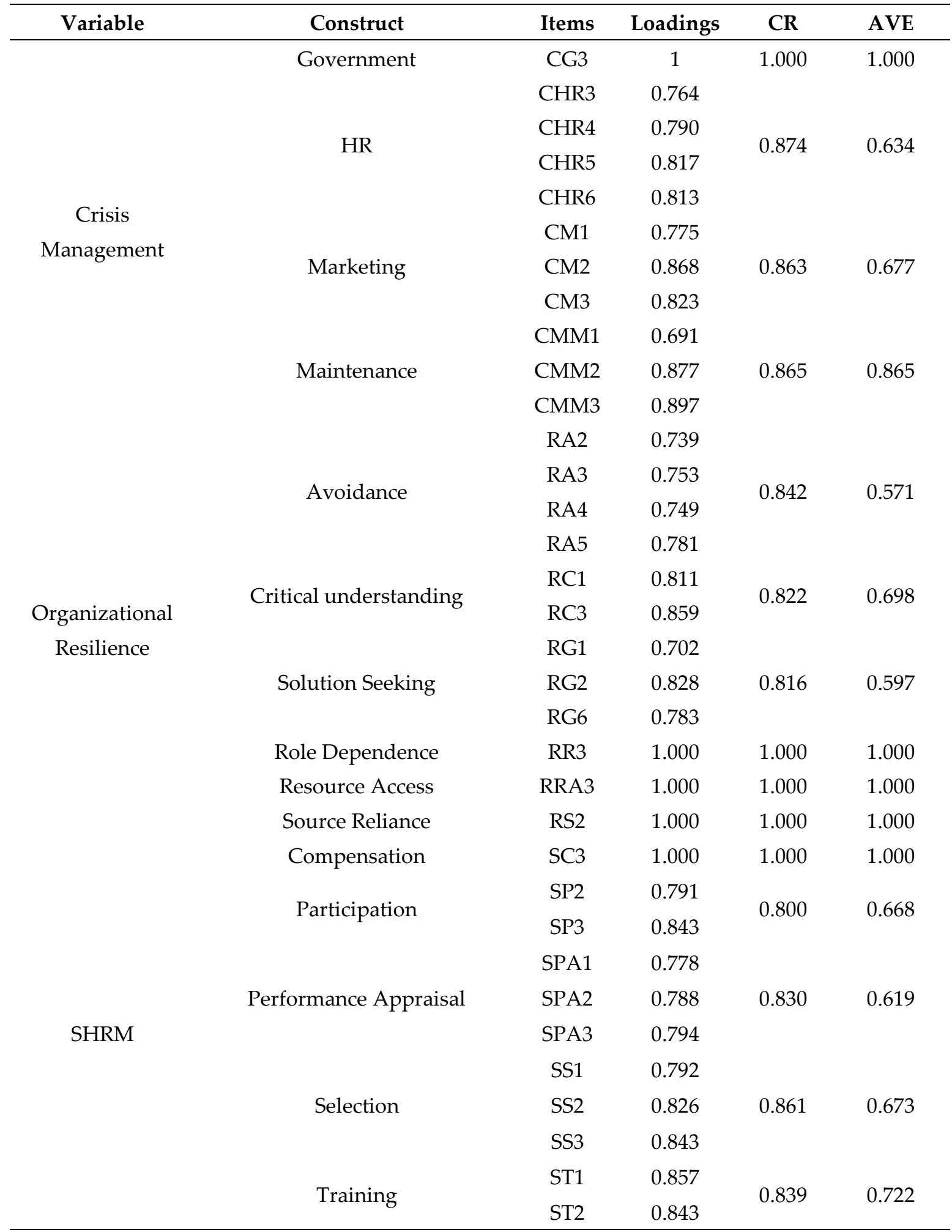

Second, by using criteria suggested by Fornell and Lacker (1981), discriminant validity was assessed. Table 3 shows that the correlations of every construct are less than the square root of average variance extracted by indicators, which suggest there is no issue of discriminant validity as well. 


\subsubsection{Structural Model}

After achieving a suggested threshold of reliability and validity of the research model, the structured model was tested next. The results of structural model are shown in Table 4. Results for the first hypothesis of this study were found insignificant, therefore we conclude that hypothesis 1 is not supported. Further, it is evident from results that there is a positive relationship between SHRM and organizational resilience $(\beta=0.092, \mathrm{p}<0.01)$, and likewise between organizational resilience and crisis management $(\beta=0.021, p<0.05)$. therefore, it is concluded that hypothesis 2 and 3 are fully supported.

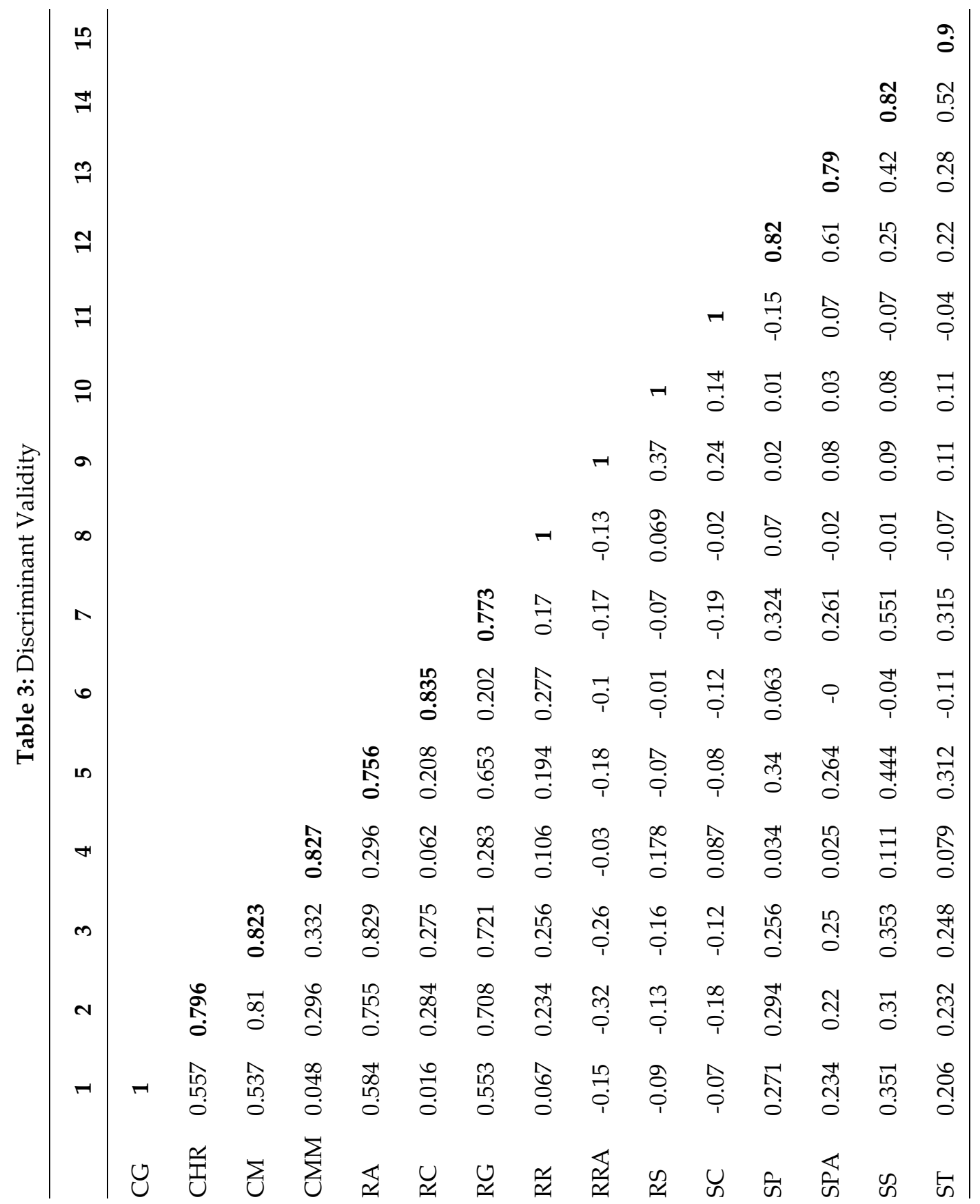

The mediation of organizational resilience between SHRM and crisis management was tested by applying recommendations of Preacher and Hayes (2004). Indirect effects were examined by performing the bootstrapping method. Results in this regard were found significant $(\beta=0.031, \mathrm{p}<$ 
0.05), which support hypothesis 4 of this study that organizational resilience mediates the relationship between SHRM and crisis management.

Table 4: Path Coefficients and Hypothesis Testing

\begin{tabular}{clccc}
\hline Hypo & \multicolumn{1}{c}{ Relationship } & Coefficient & $\begin{array}{c}\text { Confidence } \\
\text { Interval }\end{array}$ & Decision \\
\hline & & & & \\
1 & SHRM $=>$ Crisis Management & 0.001 & 0.004 & Not supported \\
2 & SHRM $=>$ Resilience & 0.092 & $0.033^{* * *}$ & Supported \\
3 & Resilience => Crisis Management & 0.021 & $0.010^{* *}$ & Supported \\
4 & SHRM $=>$ Resilience = Crisis Management & 0.031 & $0.014^{* *}$ & Supported
\end{tabular}

Level of significance: ${ }^{*} \mathrm{p}<0.1,{ }^{* *} \mathrm{p}<.05,{ }^{* * *} \mathrm{p}<0.01$

\subsection{Inner Model Evaluation}

After assessing the structural model, next the inner model was assessed by following guidelines of Hair et al. (2014). According literature, in PLS-SEM there is no standard goodness of fit statistic, therefore the quality of the model is assessed on basis of its ability to predict endogenous constructs. Hair et al. (2014) suggest the following criteria to assess the ability to predict endogenous constructs:

\subsubsection{The Coefficient of Determination $\left(\mathbf{R}^{2}\right)$}

The predictive accuracy of the model is assessed through the coefficient of determination, also known as $\mathrm{R}^{2}$. It provides combined effects of an exogenous variable on the indigenous variable. Hair et al. (2013) suggested that the predictive accuracy of PLS path model can be assessed through examining $R^{2}$ of each hypothesized relationship. Table 5 shows the values of $R^{2}$ and adjusted $R^{2}$ values of hypothesized relationships in our proposed model. $\mathrm{R}^{2}$ values that range from 0 to 1 , higher $\mathrm{R}^{2}$ values indicate better predictive accuracy of the model (Hair et al., 2013).

Table 5: The coefficient of determination $\left(R^{2}\right)$

\begin{tabular}{ccc}
\hline Variable & $\mathbf{R}^{\mathbf{2}}$ & Adjusted $\mathbf{R}^{\mathbf{2}}$ \\
\hline Crisis Management & 0.858 & 0.853 \\
Resilience & 0.844 & 0.837 \\
SHRM & 0.887 & 0.884 \\
\hline
\end{tabular}

\subsubsection{Cross-Validated Redundancy $\left(Q^{2}\right)$}

$\mathrm{Q}^{2}$ or cross-validated redundancy measures predictive relevance of inner model (Hair et al., 2014). Table 6 shows cross-validated redundancy of the proposed model. Hair et al. (2014) suggested that predictive relevance of a model is established when the value of $\mathrm{Q}^{2}$ in all hypothesized relationship exceeds zero.

Table 6: Cross-validated Redundancy

\begin{tabular}{cccc}
\hline Variable & SSO & SSE & $\mathbf{Q}^{2}=(\mathbf{1 - S S E} /$ SSO) \\
\hline Crisis Management & 700 & 524.857 & 0.25 \\
Resilience & $1,050.00$ & 891.895 & 0.151 \\
SHRM & 875 & 638.602 & 0.27 \\
\hline
\end{tabular}

\section{Discussion}

The current study is one of the initial attempts to develop and test a mediation model to explore whether SHRM influence crisis management in the manufacturing context (eg, textile sector). This 
study contributed to the literature in three ways. First, the current study contributed to the exploration of the relationship between SHRM and organizational resilience. Second, this study contributed to the exploration of the relationship between organizational resilience and crisis management. Third, the current study contributed to the exploration of the mediating role of organizational resilience between SHRM and crisis management.

Consistent with the hypothesis, results supported the significant positive relationship between SHRM and organizational resilience in manufacturing context (eg, textile sector). This finding is consistent with the research of Lengnick-Hall et al. (2011) which suggest a relationship between SHRM and organizational resilience. Results also supported the significant positive relationship between organizational resilience and crisis management as hypothesized. This finding is also in line with previous research (Parker \& Ameen, 2018; Prezelj \& Doerfel, 2017) which emphasized a relationship between organizational resilience and crisis management. Similarly, results for the indirect effect of organizational resilience between SHRM and crisis management revealed that after adding organizational resilience a mediating variable, the effect of SHRM on crisis management was significant. It suggests that organizational resilience fully mediates the relationship between SHRM and crisis management in the manufacturing context (eg, textile sector).

\subsection{Implications for Theory and Practice}

This study contributes to the body of research on organizational studies and crisis management in many ways. First, this study has provided empirical support to normal accident theory and organizational resilience, which mediates the relationship between SHRM and crisis management. Current research suggests that instead of putting efforts to avoid crises, organizations should put efforts on getting prepared to face crisis and change crisis and threats into opportunities by developing organizational resilience capabilities. Second, the current study has explored a significant positive influence of SHRM on crisis management, in this way it advances the understanding of research on SHRM as a new avenue to manage a crisis effectively. Third, the current study contributed to developing the mediation model by adding organizational resilience as a mediator between SHRM and crisis management to facilitates the relationship between the two in order to manage an organizational crisis effectively. The results support organizational resilience as a prominent mediator between SHRM and crisis management. This finding suggests that by managing human resources strategically, an organization can manage the crisis in a more effective way.

\subsection{Limitations \& Future Research}

Present study focusses on investigating the relationship between SHRM and crisis management particularly in the manufacturing context (eg, textile sector), thus the results may not be generalizable to other domains. Future research may be done in other domains to explore whether SHRM has an impact on crisis management. Although this study explored the effect of SHRM on crisis management through the mediating role of organizational resilience, it is still unclear which dimension of SHRM is a strong predictor of developing organizational resilience. Future research in this area may identify which dimension of SHRM plays a key role in developing organizational resilience in order to effectively manage the crisis.

\section{References:}

Ahmed, U., Khalid, N., Islam, DMZ., \& Abro, Z. (2019). Abuse, emotions, and workload in the distribution business: Implications for employees`engagement. International Journal of ADVANCED AND APPLIED SCIENCES, 6(8), 90-99.

Anderson, J. C., \& Gerbing, D. W. (1988). Structural equation modeling in practice: A review and recommended two-step approach. Psychological Bulletin, 103(3), 411.

Bagozzi, R. P., Yi, Y., \& Phillips, L. W. (1991). Assessing construct validity in organizational research. Administrative Science Quarterly, 421-458. 
Balu, R. (2001). How to bounce back from setbacks. Fast Company, (45), 148-155.

Bryman, A., \& Bell, E. (2015). Business Research Methods. Oxford University Press, USA.

Chen, C. J., \& Huang, J. W. (2009). Strategic human resource practices and innovation performance-The mediating role of knowledge management capacity. Journal of Business Research, 62(1), 104-114.

Cleeren, K., Dekimpe, M. G., \& van Heerde, H. J. (2017). Marketing research on product-harm crises: a review, managerial implications, and an agenda for future research. Journal of the Academy of Marketing Science, 45(5), 593-615.

Coombs, W. T. (2015). The value of communication during a crisis: Insights from strategic communication research. Business Horizons, 58(2), 141-148.

Coombs, W. T. (2015). What equivocality teaches us about crisis communication. Journal of Contingencies and Crisis Management, 23(3), 125-128.

Coombs, W. T., \& Laufer, D. (2018). Global Crisis Management-Current Research and Future Directions. Journal of International Management.

Coombs, W. T., \& Laufer, D. (2018). Global Crisis Management-Current Research and Future Directions. Journal of International Management.

Coutu, D. L. (2002). How resilience works. Harvard business review, 80(5), 46-56.

Doerfel, M. L., \& Prezelj, I. (2017). Resilience in a complex and unpredictable world. Journal of Contingencies and Crisis Management, 25(3), 118-122.

Doerfel, M. L., \& Prezelj, I. (2017). Resilience in a complex and unpredictable world. Journal of Contingencies and Crisis Management, 25(3), 118-122.

Dutton, J. E., \& Jackson, S. E. (1987). Categorizing strategic issues: Links to organizational action. Academy of Management Review, 12(1), 76-90.

Dutton, J. E., Frost, P. J., Worline, M. C., Lilius, J. M., \& Kanov, J. M. (2002). Leading in times of trauma. Harvard Business Review, 80(1), 54-61.

F. Hair Jr, J., Sarstedt, M., Hopkins, L., \& G. Kuppelwieser, V. (2014). Partial least squares structural equation modeling (PLS-SEM) An emerging tool in business research. European Business Review, 26(2), 106-121.

Fainshmidt, S., Nair, A., \& Mallon, M. R. (2017). MNE performance during a crisis: An evolutionary perspective on the role of dynamic managerial capabilities and industry context. International Business Review, 26(6), 1088-1099.

Fornell, C., \& Larcker, D. F. (1981). Structural equation models with unobservable variables and measurement error: Algebra and statistics. Journal of Marketing Research, 382-388.

Freeman, S. F., Hirschhorn, L., \& Maltz, M. (2004, August). Organization resilience and moral purpose: Sandler O'Neill and partners in the aftermath of 9/11/01. In National Academy of Management Meetings, New Orleans, LA.

Galdeano, D., Ahmed, U., Fati, M., Rehan, R., \& Ahmed, A. (2019). Financial performance and corporate social responsibility in the banking sector of Bahrain: Can engagement moderate?. Management Science Letters, 9(10), 1529-1542.

Gefen, D., Straub, D., \& Boudreau, M. C. (2000). Structural equation modeling and regression: Guidelines for research practice. Communications of the association for information systems, 4(1), 1-77.

Gittell, J. H., Cameron, K., Lim, S., \& Rivas, V. (2006). Relationships, layoffs, and organizational resilience: Airline industry responses to September 11. The Journal of Applied Behavioral Science, 42(3), 300-329.

Gittell, J. H., Cameron, K., Lim, S., \& Rivas, V. (2006). Relationships, layoffs, and organizational resilience: Airline industry responses to September 11. The Journal of Applied Behavioral Science, 42(3), 300-329. 
Hair Jr, J. F., Wolfinbarger, M., Money, A. H., Samouel, P., \& Page, M. J. (2015). Essentials of Business Research Methods. Routledge.

Hermann, C. F. (1963). Some consequences of crisis which limit the viability of organizations. Administrative Science Quarterly, 61-82.

Ishak, A. W., \& Williams, E. A. (2018). A dynamic model of organizational resilience: adaptive and anchored approaches. Corporate Communications: An International Journal, 23(2), 180-196.

Israeli, A. A., \& Reichel, A. (2003). Hospitality crisis management practices: the Israeli case. International Journal of Hospitality Management, 22(4), 353-372.

Jamrog, J. J., McCann, J. E. I., Lee, J. M., Morrison, C. L., Selsky, J. W., \& Vickers, M. (2006). Agility and resilience in the face of continuous change. American Management Association.

Kahn, W. A., Barton, M. A., Fisher, C. M., Heaphy, E. D., Reid, E. M., \& Rouse, E. D. (2018). The geography of strain: Organizational resilience as a function of intergroup relations. Academy of Management Review, 43(3), 509-529.

Kobasa, S. C., Maddi, S. R., \& Kahn, S. (1982). Hardiness and health: a prospective study. Journal of Personality and Social Psychology, 42(1), 168.

Layne, A. (2001). How to make your company more resilient. March from. http://www/fastcompany. com/articles/2001/03/odwalla. html.

Lengnick-Hall, C. A., \& Beck, T. E. (2003, August). Beyond bouncing back: The concept of organizational resilience. In National Academy of Management meetings, Seattle, WA.

Lengnick-Hall, C. A., \& Beck, T. E. (2005). Adaptive fit versus robust transformation: How organizations respond to environmental change. Journal of Management, 31(5), 738-757.

Lengnick-Hall, C. A., Beck, T. E., \& Lengnick-Hall, M. L. (2011). Developing a capacity for organizational resilience through strategic human resource management. Human Resource Management Review, 21(3), 243-255.

Madrid, D., Ahmed, U., \& Kumar, R. (2019). EXAMINING THE IMPACT OF CLASSROOM ENVIRONMENT ON ENTREPRENEURSHIP EDUCATION: CASE OF A PRIVATE UNIVERSITY IN BAHRAIN. Journal of Entrepreneurship Education, 22(1), 1-8.

Mallak, L. A. (1998). Measuring resilience in health care provider organizations. Health Manpower Management, 24(4), 148-152.

Mitroff, I. I., Pearson, C., \& Pauchant, T. C. (1992). Crisis management and strategic management: similarities, differences and challenges. Advances in Strategic Management, 8(2), 235-260.

Pahi, M. H., Hamid, K. A., Ahmed, U., \& Umrani, W. A. (2015). The unresolved dilemma of leadershipcommitment relationship: A proposed framework. Business and Economics Journal, 7(1), 2-7.

Parker, H., \& Ameen, K. (2018). The role of resilience capabilities in shaping how firms respond to disruptions. Journal of Business Research, 88, 535-541.

Pauchant, T. C., \& Mitroff, I. I. (1992). Transforming the crisis-prone organization: Preventing individual, organizational, and environmental tragedies. Jossey-Bass.

Pearson, C. M., \& Clair, J. A. (1998). Reframing crisis management. Academy of Management Review, 23(1), 5976

Perrow, C. (1984). Normal Accidents: Living with High Risk Technologies

Preacher, K. J., \& Hayes, A. F. (2004). SPSS and SAS procedures for estimating indirect effects in simple mediation models. Behavior Research Methods, Instruments, \& Computers, 36(4), 717-731. 
Preble, J. F. (1997). Integrating the crisis management perspective into the strategic management process. Journal of Management Studies, 34(5), 769-791.

Quarantelli, E. L. (1988). Disaster crisis management: A summary of research findings. Journal of Management Studies, 25(4), 373-385.

Rijpma, J. A. (1997). Complexity, tight-coupling and reliability: Connecting normal accidents theory and high reliability theory. Journal of Contingencies and Crisis Management, 5(1), 15-23.

Ringle, C. M., Wende, S., \& Becker, J. M. (2015). SmartPLS 3. Boenningstedt: SmartPLS GmbH.F

Robb, D. (2000). Building Resilient Organizations Resilient Organizations actively build and integrate Performance and Adaptive Skills. OD practitioner, 32(3), 27-32.

Rudolph, J. W., \& Repenning, N. P. (2002). Disaster dynamics: Understanding the role of quantity in organizational collapse. Administrative Science Quarterly, 47(1), 1-30.

Shrivastava, P., \& Souder, W. E. (1987). The strategic management of technological innovations: A review and a model. Journal of Management Studies, 24(1), 25-41.

Shrivastava, P., Mitroff, I. I., Miller, D., \& Miclani, A. (1988). Understanding industrial crises [1]. Journal of Management Studies, 25(4), 285-303.

Shrivastava, S., Sonpar, K., \& Pazzaglia, F. (2009). Normal accident theory versus high reliability theory: a resolution and call for an open systems view of accidents. Human Relations, 62(9), 1357-1390

Stokes, P., Smith, S., Wall, T., Moore, N., Rowland, C., Ward, T., \& Cronshaw, S. (2018). Resilience and the (micro) dynamics of organizational ambidexterity: implications for strategic HRM. The International Journal of Human Resource Management, 1-36.

Sutcliffe, K. M., \& Vogus, T. J. (2003). Organizing for resilience. Positive organizational scholarship: Foundations of a new discipline, $94,110$.

Teo, W. L., Lee, M., \& Lim, W. S. (2017). The relational activation of resilience model: How leadership activates resilience in an organizational crisis. Journal of Contingencies and Crisis Management, 25(3), 136-147.

Tokakis, V., Polychroniou, P., \& Boustras, G. (2019). Crisis management in public administration: The three phases model for safety incidents. Safety Science, 113, 37-43.

Truss, C., \& Gratton, L. (1994). Strategic human resource management: A conceptual approach. International Journal of Human Resource Management, 5(3), 663-686.

Umrani, W., Ahmed, U., \& Memon, P. (2015). Examining the absorptive capacity construct: A validation study in the Pakistani banking context. Management Science Letters, 5(12), 1053-1058.

Wah Yap, B., Ramayah, T., \& Nushazelin Wan Shahidan, W. (2012). Satisfaction and trust on customer loyalty: a PLS approach. Business Strategy Series, 13(4), 154-167.

Wold, H. (1975). Path models with latent variables: The NIPALS approach. In Quantitative Sociology (pp. 307 357).

Wold, H. (1985). Partial least squares. In S. Kotz \& N. L. Johnson (Eds.), Encyclopedia of Statistical Sciences 6 (pp. 581-591). New York: Wiley.

(C) 2019 by the author(s). Published by Annals of Contemporary Developments in Management \& HR (ACDMHR), under the terms and conditions of the Creative Commons Attribution (CC BY) license which can be accessed at http://creativecommons.org/licenses/by/4.0. 